\title{
An Endotracheal Plasmablastic Lymphoma
}

\author{
Eva M.T. Bots ${ }^{a}$ b Johan Opperman ${ }^{c}$ Fatima Bassa $^{d}$ \\ Coenraad F.N. Koegelenberg ${ }^{\mathrm{a}}$ \\ aDivision of Pulmonology, Department of Medicine, Stellenbosch University and Tygerberg Hospital, \\ Cape Town, South Africa; b Pulmonology Department, Erasmus Medical Centre, Rotterdam, The Netherlands; \\ 'Division of Anatomical Pathology, Department of Pathology, National Health Laboratory Service and \\ Stellenbosch University, Cape Town, South Africa; ${ }^{d}$ Division of Haematology, Department of Medicine, \\ Stellenbosch University and Tygerberg Hospital, Cape Town, South Africa
}

\section{Established Facts}

- Tracheal tumours encompass a small proportion of respiratory tract neoplasms, and tracheal lymphomas are very rare.

- Endotracheal plasmablastic lymphoma has never been described.

\section{Novel Insights}

- Plasmablastic lymphomas can involve the trachea.

- Macroscopically, endotracheal plasmablastic lymphoma is indistinguishable from other more common causes of tracheal tumour occurrence.

\section{Keywords}

Plasmablastic lymphoma · Endotracheal tumour · PET-CT scan

\footnotetext{
Abstract

We describe an exceptionally rare case of a male patient with newly diagnosed advanced human immunodeficiency virus (HIV) infection, who presented with a plasmablastic lymphoma involving the right maxillary alveolar ridge with associated cervical lymphadenopathy. On a staging positron emis-
}

sion tomography computed tomography (PET-CT) scan, he was incidentally found to have an endotracheal tumour involving the anterolateral aspect of the mid-trachea. The tumour appeared to be well-vascularised at bronchoscopy and was confirmed as well-differentiated plasmablastic lymphoma. Plasmablastic lymphoma is a rare form of non-Hodgkin lymphoma and is associated with HIV. Tracheal involvement to the extent seen in our patient is exceptionally rare, and, to the best of our knowledge, has never been described.

(c) 2019 The Author(s)

Published by S. Karger AG, Basel

\begin{tabular}{|c|c|c|}
\hline KARGER & $\begin{array}{l}\text { () } 2019 \text { The Author(s) } \\
\text { Published by S. Karger AG, Basel }\end{array}$ & $\begin{array}{l}\text { Karger } \\
\text { Open access }\end{array}$ \\
\hline $\begin{array}{l}\text { E-Mail karger@karger.com } \\
\text { www.karger.com/res }\end{array}$ & $\begin{array}{l}\text { This article is licensed under the Creativ } \\
\text { NonCommercial-NoDerivatives } 4.0 \text { Inter } \\
\text { NC-ND) (http://www.karger.com/Servi } \\
\text { Usage and distribution for commercial pu } \\
\text { tribution of modified material requires wr }\end{array}$ & $\begin{array}{l}\text { Oommons Attribution- } \\
\text { ional License (CC BY- } \\
\text { OpenAccessLicense). } \\
\text { oses as well as any dis- } \\
\text { n permission. }\end{array}$ \\
\hline
\end{tabular}

Eva Marianne Theresa Bots

Erasmus MC Longgeneeskunde

Erasmus Medical Centre

Postbus 2040, NL-3000 CA Rotterdam (The Netherlands)

E-Mail e.bots@erasmusmc.nl 


\section{Introduction}

Tracheal tumours encompass a small proportion of respiratory tract neoplasms, accounting for only about $2 \%$ of airway malignancies and with an incidence of 0.1 per 100,000 people per year [1]. Squamous-cell carcinoma is the most common tracheal tumour, followed by adenoid cystic carcinoma [1]. Symptoms are usually attributable to the intraluminal component of the tumour causing obstruction of the airway with stridor, dyspnoea, wheezing, haemoptysis, and cough.

The true incidence of secondary tracheal tumours, defined as tumours within the trachea but which do not originate from the trachea, is unknown. Tracheal involve- ment may occur because of direct invasion, or hematogenous or lymphatic spread, and the most common aetiologies are thyroid cancer, oesophageal tumour, and squamous-cell carcinoma of the lung [2].

Endotracheal lymphoma, albeit rare, has been reported, particularly polypoid nodules secondary to mucosaassociated lymphoid tissue (MALT) lymphoma [3].

\section{Case Report}

A 40-year-old male smoker without any significant medical history presented with a 2-month history of a soft-tissue swelling of the right maxillary area, which persisted after teeth extractions. He was found to have a large ulcerative lesion involving
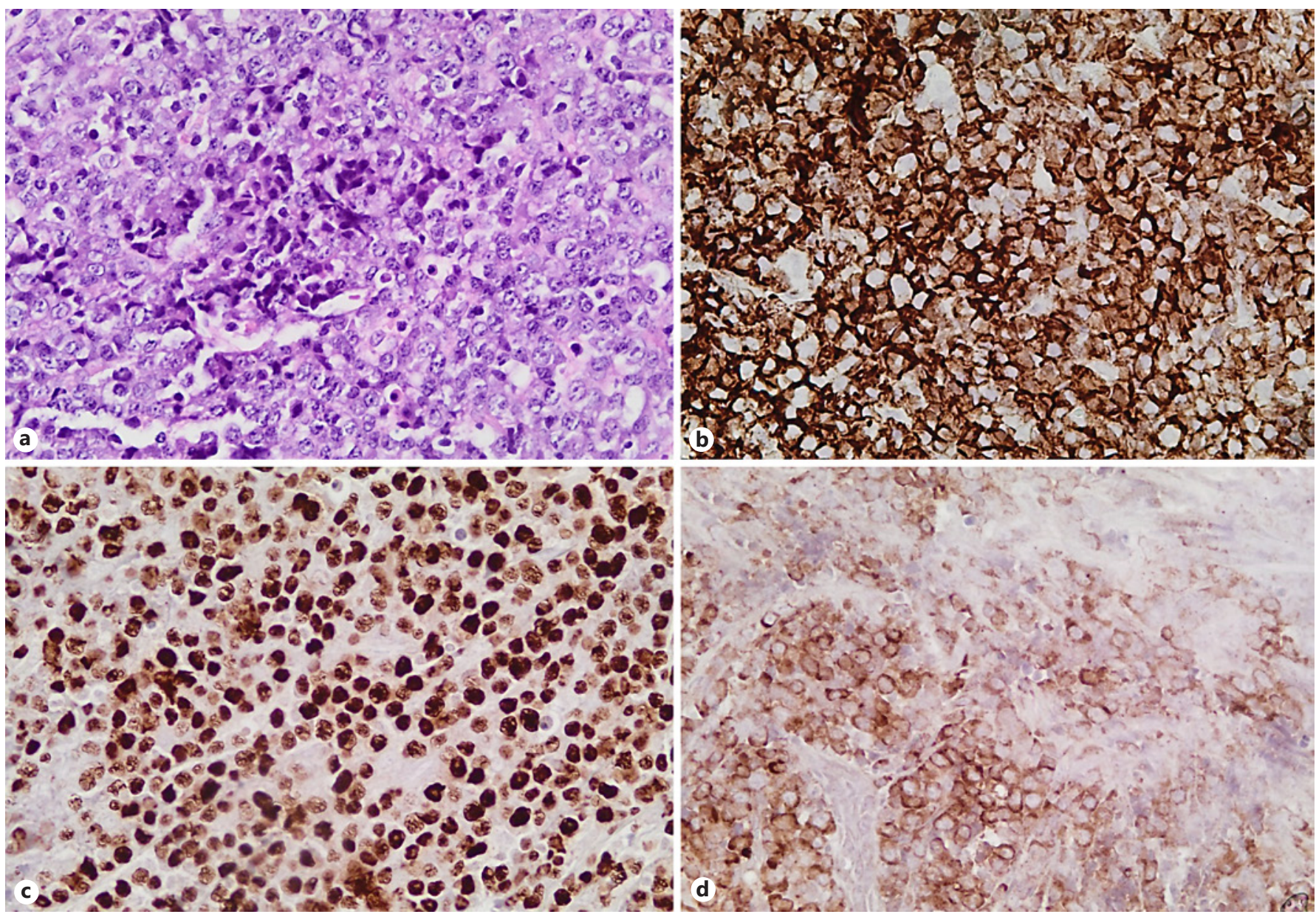

Fig. 1. a Biopsy of the maxillary lesion showed tumour cells exhibiting predominantly immunoblastic differentiation with focal plasmablastic differentiation. The tumour cells showed strong immunoreactivity with plasma cell-associated antigens CD138, MUMI, EMA, and CD38, variable positivity with the B cell markers CD45 and CD79a, and was completely negative for CD20, all compatible with a high-grade B cell non-Hodgkin lymphoma, par- ticularly plasmablastic lymphoma. Cytoplasmic $\kappa$ light chain restriction and EBV were present. a Maxillary tumour with oral mucosa with a submucosal tumour. $\times 200$. b Submucosal infiltrate comprising sheets of immunoblastic cells exhibiting immunoreactivity with CD138. c Nuclear positivity with EBER-in situ hybridization. d Cytoplasmic $\kappa$ light chain restriction. $\times 400$. 

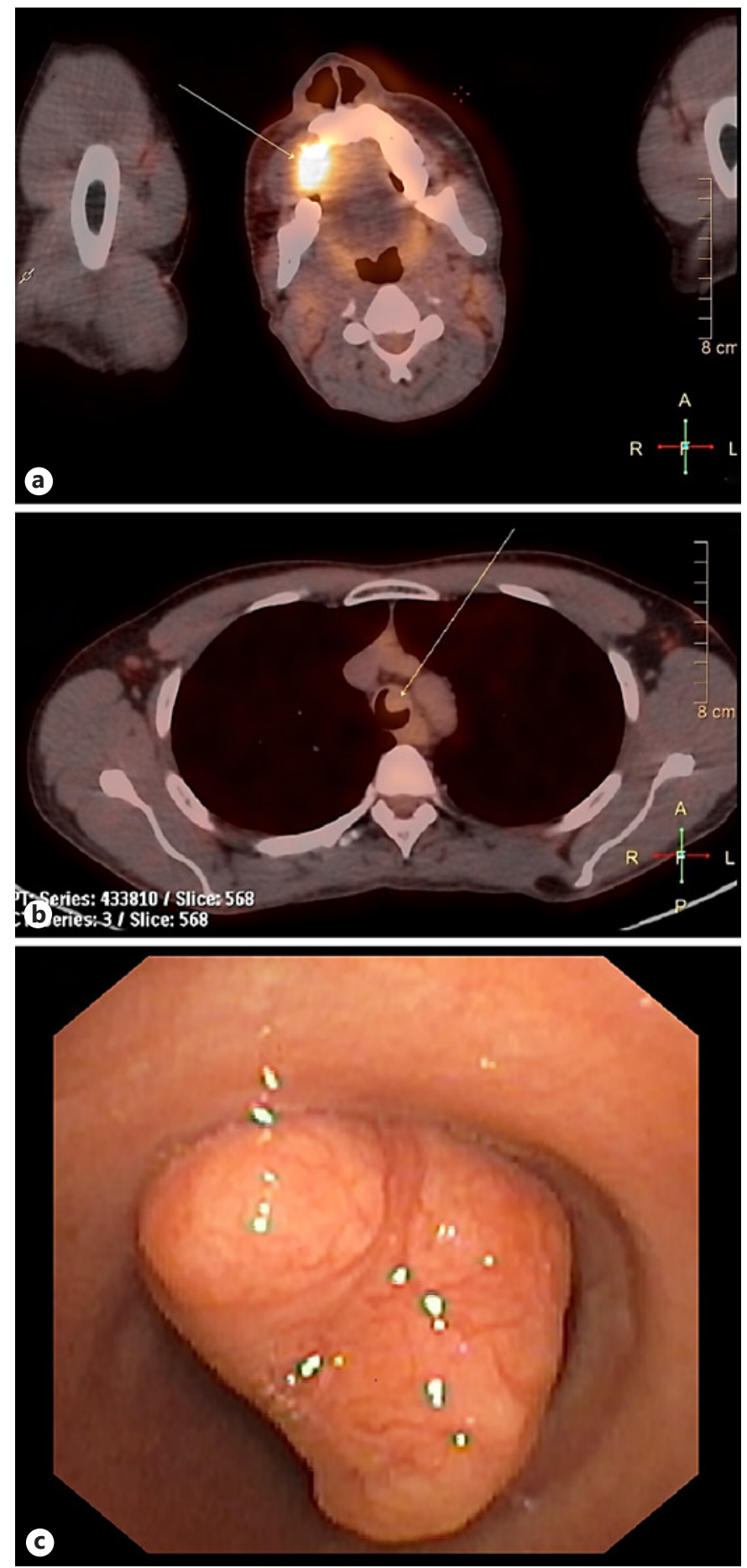

Fig. 2. a Staging PET-CT scan showed intense FDG uptake in the known right maxillary tumour, with associated destruction of the right maxillary bone but no evidence of intracranial extension. b It also showed a soft-tissue mass with mild FDG uptake involving the anterolateral aspect of the mid trachea. c At bronchoscopy, a well-vascularised tumour was seen with no other endobronchial abnormalities. the right maxillary alveolar ridge, with associated cervical lymphadenopathy. A biopsy of the maxillary lesion showed plasmacytic differentiation, with tumour cells exhibiting strong immunoreactivity, variable positivity with B cell markers, cytoplasmic $\kappa$ light chain restriction, and the presence of Epstein-Barr virus (EBV, Fig. 1), all compatible with a diagnosis of high-grade B cell non-Hodgkin lymphoma (NHL), in particular plasmablastic lymphoma.

The patient was referred to our institution and subsequently found to be positive for human immunodeficiency virus (HIV) with a CD4 count of 69 cells $/ \mathrm{mm}^{3}$. He was anti-retroviral therapy (ART)-naïve.

Routine staging positron emission tomography computed tomography (PET-CT) was performed and showed intense ${ }^{18} \mathrm{~F}$-labelled fluoro-2-deoxyglucose (FDG) uptake in the known right maxillary tumour (Fig. 2a), with associated bony destruction. An endotracheal tumour measuring $14 \times 11 \mathrm{~mm}$ (Fig. 2b), with less intense FDG uptake, was also noted. In view of the differential FDG uptake, a biopsy was advised.

The tumour appeared to be well-circumscribed and vascularised at bronchoscopy, with an appearance compatible with a primary tracheal tumour (Fig. 2c). Conventional fine-needle aspiration of the tumour did not yield diagnostic material (on rapid onsite evaluation), and forceps biopsies were subsequently cautiously obtained.

The histology of the endotracheal lesion also showed plasmacytic differentiation, with tumour cells exhibiting strong immunoreactivity with plasma cell-associated antigens as noted in the maxillary tumour, variable positivity with B cell markers, and the presence of EBV, all compatible with a diagnosis of plasmablastic lymphoma (Fig. 3). Of interest is the fact that the endotracheal tumour cells were more mature, with plasmacytic differentiation.

The levels of bone marrow aspirate, trephine, and serum calcium as well as renal function were normal, and the serum protein electrophoresis revealed a small polyclonal band. The patient was commenced on combination chemotherapy and ART, and has had a good clinical response to date.

\section{Discussion}

Of people living with HIV, up to $40 \%$ will develop malignancy, with approximately $10 \%$ developing NHL $[4,5]$. The most common systemic NHL subtypes seen in HIVpositive individuals are diffuse large B cell lymphoma (75\%) and Burkitt lymphoma [6].

Plasmablastic lymphoma accounts for $<3 \%$ of NHL seen in HIV-positive patients [7, 8]. It is a rare form of NHL that usually occurs in the oral cavity and these individuals are often positive for EBV $[9,10]$. Involvement of the paranasal sinuses, skin, soft tissue, larynx, lung, and anorectal region have been described [11]. Tracheal involvement is exceptionally rare, and, to the best of our knowledge, has never been described.

Co-infection with Human herpesvirus 8 has also been reported in plasmablastic lymphoma, with a prevalence 


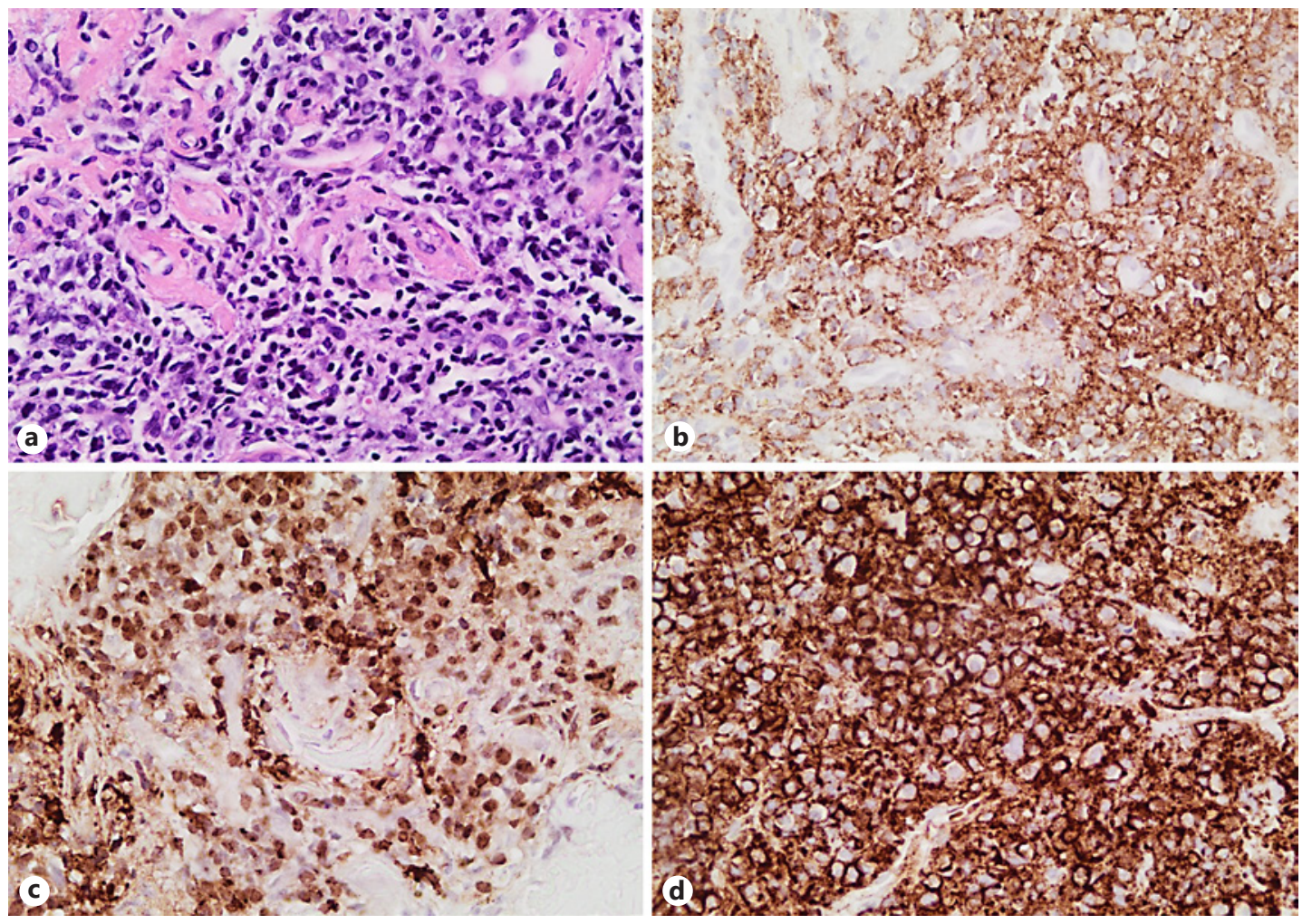

Fig. 3. The histology of the endotracheal lesion also showed plasmacytic differentiation, with tumour cells exhibiting strong immunoreactivity with plasma cell-associated antigen CD138, MUMI, EMA, and CD38, but variable positivity with the B cell markers CD45 and CD79a, and completely negative for CD20. The endotracheal tumour cells differed cytomorphologically from the oral cavity tumour, showing a more mature plasmacytic differentiation. a Respiratory-type mucosa with a submucosal tumour. $\times 200$. b Submucosal infiltrate comprising of sheets of cells with a plasmacytic differentiation, exhibiting immunoreactivity with CD138 (c) and positive for EBER-in situ hybridization $(\mathbf{d} ; \times 400)$.

ranging from 17 to $100 \%[12,13]$. Another rare genetic subtype of plasmablastic lymphoma has rearrangements of the ALK tyrosine kinase gene.

A review of 157 cases of plasmablastic lymphoma reported that early clinical stage and complete response to chemotherapy are associated with a better outcome. The best approach to therapy remains unclear, and standard CHOP (cyclophosphamide, hydroxydaunorubicin [Adriamycin], vincristine [Oncovin], and prednisone or prednisolone) is considered an inadequate therapy [14]. The American National Comprehensive Cancer Network guidelines recommend a more intensive regimen, as at least 1 study has suggested better outcomes using more aggressive chemotherapy such as that used for Burkitt lymphoma [15].

In conclusion, plasmablastic lymphoma is an extremely rare form of HIV-related lymphoma, and endotracheal involvement is with plasmablastic lymphoma is not typically seen, which makes this possibly the first properly documented case.

\section{Acknowledgments}

We acknowledge the contribution made by Dr Candice Sher (Consultant Pathologist at Stellenbosch University) in the interpretation of the histology.

\section{Statement of Ethics}

Written informed consent was obtained from the patient.

\section{Disclosure Statement}

The authors have nothing to declare. 


\section{Funding Sources}

There was no funding.

\section{References}

1 Diaz-Mendoza J, Debiane L, Peralta AR, Simoff M. Tracheal tumors. Curr Opin Pulm Med. 2019;25:336-43.

2 Madariaga ML, Gaissert HA. Secondary tracheal tumors: a systematic review. Ann Cardiothorac Surg. 2018 Mar;7(2):183-96.

3 Minami D, Ando C, Sato K, Moriwaki K, Sugahara F, Nakasuka T, et al. Multiple Mucosaassociated Lymphoid Tissue Lymphoma of the Trachea. Intern Med. 2017 Nov;56(21): 2907-11.

4 Burgi A, Brodine S, Wegner S, Milazzo M, Wallace MR, Spooner K, et al. Incidence and risk factors for the occurrence of non-AIDSdefining cancers among human immunodeficiency virus-infected individuals. Cancer. 2005 Oct;104(7):1505-11.

5 Engels EA, Yanik EL, Wheeler W, Gill MJ, Shiels MS, Dubrow R, et al.; North American AIDS Cohort Collaboration on Research and Design of the International Epidemiologic Databases to Evaluate AIDS; North American AIDS Cohort Collaboration on Research and Design of the International Epidemiologic Databases to Evaluate AIDS. Cancer-Attributable Mortality Among People With Treated

\section{Author Contributions}

E.M.T.B. and C.F.N.K. wrote the manuscript, which was then reviewed by all co-authors.
Human Immunodeficiency Virus Infection in North America. Clin Infect Dis. 2017 Aug: 65(4):636-43.

6 Mantina H, Wiggill TM, Carmona S, Perner Y, Stevens WS. Characterization of Lymphomas in a high prevalence HIV setting. J Acquir Immune Defic Syndr. 2010 Apr;53(5):65660.

7 Stephenson K, Peer S, Govender D, Fagan JJ. Plasmablastic lymphoma of the larynx: report of two cases. J Laryngol Otol. 2013 Jan;127(1): 96-9.

8 Carbone A. AIDS-related non-Hodgkin's lymphomas: from pathology and molecular pathogenesis to treatment. Hum Pathol. 2002 Apr;33(4):392-404.

9 Abayomi EA, Somers A, Grewal R, Sissolak G Bassa F, Maartens D, et al. Impact of the HIV epidemic and Anti-Retroviral Treatment policy on lymphoma incidence and subtypes seen in the Western Cape of South Africa, 2002-2009: preliminary findings of the Tygerberg Lymphoma Study Group. Transfus Apheresis Sci. 2011 Apr;44(2):161-6.

10 Arvey A, Ojesina AI, Pedamallu CS, Ballon G, Jung J, Duke F, et al. The tumor virus land- scape of AIDS-related lymphomas. Blood. 2015 May;125(20):e14-22.

11 Castillo JJ, Bibas M, Miranda RN. The biology and treatment of plasmablastic lymphoma. Blood. 2015 Apr;125(15):2323-30.

12 Riedel DJ, Gonzalez-Cuyar LF, Zhao XF, Redfield RR, Gilliam BL. Plasmablastic lymphoma of the oral cavity: a rapidly progressive lymphoma associated with HIV infection. Lancet Infect Dis. 2008 Apr;8(4):261-7.

13 Cioc AM, Allen C, Kalmar JR, Suster S, Baiocchi R, Nuovo GJ. Oral plasmablastic lymphomas in AIDS patients are associated with human herpesvirus 8. Am J Surg Pathol. 2004 Jan;28(1):41-6.

14 Castillo JJ, Winer ES, Stachurski D, Perez K, Jabbour M, Milani C, et al. Prognostic factors in chemotherapy-treated patients with HIV associated Plasmablastic lymphoma. Oncologist. 2010;15(3):293-9.

15 Teruya-Feldstein J, Chiao E, Filippa DA, Lin O, Comenzo R, Coleman M, et al. CD20-negative large-cell lymphoma with plasmablastic features: a clinically heterogenous spectrum in both HIV-positive and -negative patients. Ann Oncol. 2004 Nov;15(11):1673-9. 